\title{
Environmental Acoustic Enrichment Promotes Recovery from Developmentally Degraded Auditory Cortical Processing
}

\author{
Xiaoqing Zhu, ${ }^{1}$ Fang Wang, ${ }^{1}$ Huifang Hu, ${ }^{1}$ Xinde Sun, ${ }^{1}$ Michael P. Kilgard, ${ }^{2}$ Michael M. Merzenich, ${ }^{3}$ \\ and Xiaoming Zhou ${ }^{1}$ \\ ${ }^{1}$ Key Laboratory of Brain Functional Genomics of Ministry of Education, Shanghai Key Laboratory of Brain Functional Genomics, School of Life Sciences, \\ East China Normal University, Shanghai 200062, China, ${ }^{2}$ School of Behavioral and Brain Sciences, University of Texas at Dallas, Richardson, Texas 75080 , \\ and ${ }^{3}$ Keck Center for Integrative Neuroscience, University of California, San Francisco, California 94143
}

It has previously been shown that environmental enrichment can enhance structural plasticity in the brain and thereby improve cognitive and behavioral function. In this study, we reared developmentally noise-exposed rats in an acoustic-enriched environment for $\sim 4$ weeks to investigate whether or not enrichment could restore developmentally degraded behavioral and neuronal processing of sound frequency. We found that noise-exposed rats had significantly elevated sound frequency discrimination thresholds compared with agematched naive rats. Environmental acoustic enrichment nearly restored to normal the behavioral deficit resulting from early disrupted acoustic inputs. Signs of both degraded frequency selectivity of neurons as measured by the bandwidth of frequency tuning curves and decreased long-term potentiation of field potentials recorded in the primary auditory cortex of these noise-exposed rats also were reversed partially. The observed behavioral and physiological effects induced by enrichment were accompanied by recovery of cortical expressions of certain $\mathrm{NMDA}_{\text {and }} \mathrm{GABA}_{\mathrm{A}}$ receptor subunits and brain-derived neurotrophic factor. These studies in a rodent model show that environmental acoustic enrichment promotes recovery from early noise-induced auditory cortical dysfunction and indicate a therapeutic potential of this noninvasive approach for normalizing neurological function from pathologies that cause hearing and associated language impairments in older children and adults.

Key words: BDNF; environmental acoustic enrichment; frequency discrimination performance; frequency selectivity; primary auditory cortex

\section{Introduction}

Functional development of the mammalian auditory system is substantially influenced by the nature of environmental acoustic inputs in early life (Sanes and Bao, 2009; Schreiner and Polley, 2014). For example, it has been shown that pulsed noise exposure during early postnatal development persistently degrades frequency tuning, temporal responses, and directional selectivity of neurons recorded in the primary auditory cortex (A1) in adulthood (Zhang et al., 2002; Zhou and Merzenich, 2007, 2008, 2009; Insanally et al., 2010; Pan et al., 2011). The enduring degradation of response specificities of neurons following noise exposure

Received Dec. 19, 2013; revised Feb. 6, 2014; accepted March 4, 2014.

Author contributions:X.Zhou designed research; X.Zhu, F.W., H.H., and X. Zhou performed research;X.Zhu, F.W., H.H., X.S., M.P.K., M.M.M., and X. Zhou analyzed data; X. Zhou wrote the paper.

This work was supported by the National Natural Science Foundation of China (31271178), the Shanghai Pujiang Talent Plan (13PJ1402900), and the Minhang Talent Development Fund. We thank Drs. Aage Moller, Christoph Schreiner, David Blake, Hubert Dinse, and Nina Kraus for their comments and suggestions on earlier versions of this paper.

The authors declare no competing financial interests.

Correspondence should be addressed to X. Zhou, Key Laboratory of Brain Functional Genomics of Ministry of Education, Shanghai Key Laboratory of Brain Functional Genomics, School of Life Sciences, East China Normal University, Shanghai 200062, China. E-mail: xmzhou@bio.ecnu.edu.cn.

DOI:10.1523/JNEUROSCI.5310-13.2014

Copyright $\odot 2014$ the authors $\quad 0270-6474 / 14 / 345406-10 \$ 15.00 / 0$ presumably impairs the cortical processing of behaviorally important acoustic inputs in later life. In human populations, fundamental deficits in auditory cortical processing have been argued to contribute to delayed and impaired language development, and have been shown to put impaired children at risk for reading disabilities (Wright et al., 1997; Nagarajan et al., 1999; Ahissar et al., 2001; Paterson et al., 2006).

Environmental enrichment has well demonstrated positive effects on brain development by accelerating structural and functional plasticity (Rampon et al., 2000; van Praag et al., 2000; Bartoletti et al., 2004; Del Arco and Segovia, 2007; Bose et al., 2010; Komitova et al., 2013; Wang et al., 2013). Earlier behavioral studies have shown that environmental enrichment improves an animal's visual acuity and spatial learning capacity (Van Waas and Soffié, 1996; Williams et al., 2001; Bartoletti et al., 2004; Leggio et al., 2005; Dhanushkodi et al., 2007; Tognini et al., 2012; Baldini et al., 2013). In agreement with these results, physiological studies have demonstrated that environmental enrichment narrows orientation tuning of neurons in the visual cortex and sharpens topographic organization of the somatosensory cortex (Beaulieu and Cynader, 1990; Coq and Xerri, 1998; Sale et al., 2007). In the auditory cortex, it has been shown that environmental enrichment paired with passive acoustic stimulation in- 
creases response strength but decreases response threshold of neurons (Dinse, 2004; Engineer et al., 2004). Such paradigm also alters cortical temporal processing and spatial representation of sound (Percaccio et al., 2005, 2007; Kilgard et al., 2007; Cai et al., 2009, 2010; Jakkamsetti et al., 2012). While these studies that demonstrate environmental acoustic enrichment promotes plasticity in the auditory cortex were all conducted on normal animals, it has not been determined whether enrichment could restore developmentally degraded auditory cortical processing.

In this study we reared developmentally noise-exposed (NE) rats in an acoustic-enriched environment for $\sim 4$ weeks. Sound frequency discrimination performance for these rats was evaluated and frequency receptive fields of A1 neurons were documented at the cessation of enriched rearing. Recorded data then were compared with those of same-age NE rats, as well as naive controls, to determine the enrichment-induced restoration of noise-impaired behavioral and cortical neuronal processing of spectral information of sound. In addition, shifts in cortical longterm potentiation (LTP) magnitudes were assessed and changes in cortical expressions of certain molecules, including excitatory NMDA receptor subunits NR2a and NR2b; AMPA receptor subunit GluR2; inhibitory $\mathrm{GABA}_{\mathrm{A}}$ receptor subunits $\alpha 1, \alpha 3, \beta 2$, and $\beta 3$; and brain-derived neurotrophic factor (BDNF), were determined to elucidate the synaptic and molecular mechanisms underlying enrichment-induced cortical plasticity.

\section{Materials and Methods}

Procedures. All procedures were approved by the Institutional Animal Care and Use Committee and complied with National Institutes of Health standards.

Noise exposure. Female rat pups (Sprague Dawley) with their mothers were placed in a sound-shielded test chamber for noise exposure from postnatal day 10-38 (P10-P38). Fifty millisecond noise pulses (5 ms rise-decay time) delivered at $65 \mathrm{~dB}$ SPL were applied from a speaker (flat response $\pm 2 \mathrm{~dB}$ in the frequency range $0.8-30 \mathrm{kHz}$ ) placed $20 \mathrm{~cm}$ above the rats at five pulses per second (pps) at $1 \mathrm{~s}$ intervals. A reversed $12 \mathrm{~h}$ light/dark cycle and constant humidity and temperature were maintained during noise exposure. The weights of all pups were continuously monitored, and there was no weight loss compared with age-matched naive control rats, indicating normal lactation.

After the cessation of noise exposure at P38, NE rats were randomly divided into two groups: those reared either in a standard housing environment (i.e., NE rats) or those reared in an acoustic-enriched environment (i.e., AEE rats) for 4 weeks when tested at approximately P66 (Fig. $1 A$ ). The researcher was kept blind to the group identity of the animals during experiments.

AEE. As in our previous studies (Cai et al., 2009, 2010), enriched conditions consisted of three large cages $(90 \times 80 \times 100 \mathrm{~cm})$ that contained running wheels, seesaws, balls, tunnels, cubes, and cone toys (Fig. $1 B)$. There were also stairs, ramps, and platforms in each cage. Food and water were provided on the platform, which could only be accessed via the stairs or ramps. Eight speakers were fixed around the cage oriented in different directions. Pure tone pips ( $50 \mathrm{~ms}$ duration with a $5 \mathrm{~ms}$ risedecay time, $1 \mathrm{pps})$ with different frequencies $(1-30 \mathrm{kHz})$ were phonated randomly from different speakers. All tone intensities were set at $65 \mathrm{~dB}$ SPL. Three cages (5-6 rats per cage) were decorated in different styles. They had the same ingredients, but with a different number or position. Rats in each cage were switched to a different cage every 3 or $4 \mathrm{~d}$ to maintain novelty. Normal housing conditions for $\mathrm{NE}$ and naive rats consisted of smaller cages $(45 \times 35 \times 35 \mathrm{~cm})$ with two rats per cage. These rats had ad libitum access to food and water.

Behavioral testing. The behavioral examination consisted of two phases: a procedural-learning phase and a perceptual-testing phase. In the first phase, rats were trained to discriminate a target tonal stimulus (8 $\mathrm{kHz}$ ) from a nontarget with frequency of 0.8 octave separation from 8 $\mathrm{kHz}$. Rats were rewarded for making a go response within a limited time window after the presentation of a target tone. During the perceptualtesting phase, the sound frequency discrimination ability was tested when nontargets were randomly chosen from tonal stimuli of various frequencies (i.e., 0.1 octave, 0.2 octave, 0.4 octave, 0.6 octave, or 0.8 octave separation from $8 \mathrm{kHz}$, respectively). Stimuli were $60 \mathrm{~dB}$ SPL, 50 $\mathrm{ms}$ tone pips with $5 \mathrm{~ms}$ rise-decay time. Only one tone with specific frequency was presented in each trial.

Training and testing were conducted in an acoustically transparent operant training chamber $(20 \times 20 \times 18 \mathrm{~cm})$ enclosed within a soundattenuated chamber. An input and output system (photobeam detector, food dispenser, sound card, and house light; Med Associates) was used to control behavioral training or testing.

The rats' behavior was reduced to "go" or "no-go" responses. Rats were in the go state when the photobeam of the nose-poke device was interrupted (i.e., a nose-poke response). All other states were considered no-go. For a given trial, rats could elicit one of five reinforcement states. The first four states were given by the combinations of responses (go or no-go) and stimulus properties (target or nontarget). A go response within $3 \mathrm{~s}$ of a target was scored as a "hit"; a failure to respond within this time window was scored as a "miss." A go response within $3 \mathrm{~s}$ of a nontarget stimulus was scored as a "false positive," and the absence of response was scored as a "withhold." The fifth state, "false alarm," was defined as a go response that occurred $3 \mathrm{~s}$ or more after stimulus presentation. A hit triggered the delivery of a $45 \mathrm{mg}$ food pellet (Bio Serve). A miss, false positive, or false alarm initiated a $9 \mathrm{~s}$ "time-out" period, during which time the house lights were turned off and no stimuli were presented. A withhold did not produce a reward or time-out.

Trials were grouped into blocks of 50. Rats were trained with eight blocks per day during the procedural-learning phase and were tested with three blocks on the day of testing. At the conclusion of each training or testing block, a hit ratio ( $\mathrm{H}$; number of hits/number of target trials) and a false positive ratio (F; number of false-positives/number of nontarget trials) were calculated. The discrimination ability was quantified by the performance score, calculated as $\mathrm{H}-(\mathrm{F} \times \mathrm{H})$ and expressed as a percentage.

Cortical recording. Rats used for cortical recording were not those already used for behavioral testing but were otherwise treated in the same way. Under pentobarbital anesthesia $(50 \mathrm{mg} / \mathrm{kg}$ body weight), cortical responses were recorded with parylene-coated tungsten microelectrodes (1-2 $\mathrm{M} \Omega$ at $1 \mathrm{kHz} ; \mathrm{FHC})$. At each recording site the microelectrode was lowered orthogonally into the cortex to a depth of $\sim 550 \mu \mathrm{m}$ (layers IV-V) where evoked spikes of a neuron or a small cluster of neurons was recorded. Acoustic stimuli were generated and delivered to the contralateral ear relative to the recording site through a calibrated earphone with a sound tube positioned inside the external auditory meatus. A software package (SigCal, SigGen, and Brainware; Tucker-Davis Technology) was used to calibrate the earphone, generate acoustic stimuli, monitor cortical response properties on-line, and store data for off-line analysis.

Frequency tuning curves of A1 neurons were reconstructed by presenting pure tones ( $25 \mathrm{~ms}$ duration) of 50 frequencies $(1-30 \mathrm{kHz}$ ) at eight sound intensities ( $0-70 \mathrm{~dB}$ SPL in $10 \mathrm{~dB}$ increments) in a random, interleaved sequence at a rate of 2 pps. Overlap index of frequency tuning curves was computed by first transforming the frequency tuning curves recorded from two cortical sites into $1 \mathrm{D}$ vectors and then calculating the peak of the normalized correlation coefficient between the two vectors produced (de Villers-Sidani et al., 2010; Zhou et al., 2011). Indices were obtained for all pairs of recording sites with various distances within a single animal.

The overall boundaries of the A1 were functionally determined using nonresponsive sites and responsive sites that did not have a well defined pure tone-evoked response area (i.e., non-A1 sites; Zhou and Merzenich, 2009, 2012). As previously described (Polley et al., 2006, 2007; Profant et al., 2013), A1 has a unique rostral-to-caudal tonotopy and reliable neuronal responses to tone pips of selective frequencies.

LTP induction. Rats used for LTP induction were not those already used for behavioral testing or cortical recording but were otherwise treated in the same way. Brain slices from auditory cortex were prepared as described previously (Mao et al., 2006; Zhang et al., 2013). Briefly, rats were deeply anesthetized with sodium pentobarbital $(75 \mathrm{mg} / \mathrm{kg}$ body 
weight) and quickly perfused with ice-cold artificial CSF (ACSF). The ACSF contained the following (in $\mathrm{mm}$ ): $\mathrm{NaCl} 119, \mathrm{KCl} 2.5, \mathrm{CaCl}_{2} 2.5$, $\mathrm{MgSO}_{4} 1.3$, D-glucose $11, \mathrm{NaH}_{2} \mathrm{PO}_{4} 1$, and $\mathrm{NaHCO}_{3} 26.2$, pH 7.4. Immediately after decapitation, the brain was carefully extracted and immersed in ice-cold ACSF aerated with $95 \% \mathrm{O}_{2}$ and $5 \% \mathrm{CO}_{2}$. Tissue containing auditory cortex was isolated and $400-\mu \mathrm{m}$-thick coronal slices prepared in ice-cold ACSF using a vibratome. The location of A1 was determined according to Paxinos and Watson's (1998) atlas and studies by Polley et al. (2007). After incubating at room temperature for at least $1 \mathrm{~h}$, the slices were transferred to a recording chamber and sandwiched between two pieces of nylon mesh for electrophysiological recording of evoked field potentials.

The electrode for electrical stimulation (twisted $70 \mu \mathrm{m}$ nichrome wires insulated except at the tips) was placed on cortical layer VI-white matter (WM) border, and that for recording (a glass pipette electrode with tip diameter of $1.0-1.5 \mu \mathrm{m}$ ) was placed in layer III/IV. A silver wire was used as a ground. After a $24 \mathrm{~min}$ stable baseline, the theta burst stimulation (TBS; five pulses per burst at $100 \mathrm{~Hz}$ with bursts repeated at $5 \mathrm{~Hz}$ for a total of 11 bursts) was applied to the WM and the amplitudes of field potentials were recorded every $4 \mathrm{~min}$ for $120 \mathrm{~min}$ following the cessation of TBS. During recording, fresh ACSF (aerated with 95\% $\mathrm{O}_{2}$ and 5\% $\mathrm{CO}_{2}$ ) was continuously perfused into the recording chamber.

Quantitative immunoblotting. Rats used for quantitative immunoblotting again were not those already used for behavioral testing or cortical recording but were otherwise treated in the same way. Rats were deeply anesthetized with sodium pentobarbital ( $75 \mathrm{mg} / \mathrm{kg}$ body weight). Immediately after decapitation, brains were removed and auditory cortices (Paxinos and Watson, 1998; Polley et al., 2007) were isolated and homogenized in ice-cold homogenization buffer.

Quantitative immunoblotting assays were performed as described previously (Cai et al., 2010; Guo et al., 2012; Zhang et al., 2013). Briefly, the concentration of total proteins was first determined using the bicinchoninic acid assay. Proteins were separated on a 7.5\% SDSpolyacrylamide gel and then transferred to a nitrocellulose membrane. After both primary and secondary antibody incubations, proteins were visualized using enhanced chemiluminescence followed by exposure to the $x$-ray film. Primary antibodies used included anti-NMDA NR2a and NR2b (Millipore); anti-GluR2 (Millipore); anti-GABA ${ }_{A} \alpha 1, \alpha 3, \beta 2$, and $\beta 3$ (Millipore); and anti- $\beta$-actin (Sigma).

The density of each band on Western blotting was measured and the relative level of each protein was calculated as the ratio of target protein band compared with the $\beta$-actin loading control band.

Immunohistochemistry. Rats used for immunohistochemistry were not those already used for behavioral testing or cortical recording but were otherwise treated in the same way. As in our earlier studies (de VillersSidani et al., 2010; Zhou and Merzenich, 2012), rats were deeply anesthetized with sodium pentobarbital (75 $\mathrm{mg} / \mathrm{kg}$ body weight) and were perfused intracardially with saline solution followed by $4 \%$ paraformaldehyde in $0.1 \mathrm{~m}$ potassium PBS, $\mathrm{pH}$ 7.2. Brains were removed and placed in the same fixative containing $20 \%$ sucrose for $12-24 \mathrm{~h}$. Fixed material was cut in the coronal plane on a freezing microtome at $40 \mu \mathrm{m}$ thickness. Free-floating sections were pre-incubated in a blocking solution to suppress nonspecific binding. The sections were then incubated at $4^{\circ} \mathrm{C}$ for $48-72 \mathrm{~h}$ in anti-BDNF (Millipore) or anti-NeuN (Millipore). After exposing to biotinylated IgG (Vector Laboratories) at room temperature for $1 \mathrm{~h}$, samples were treated further with streptavidin-conjugated $\mathrm{Cy} 3$ (Jackson ImmunoResearch) again at room temperature for $1 \mathrm{~h}$.

Tissues from different rat groups were always processed together during immunostaining procedures to limit variation related to antibody penetration, incubation time, and the postsectioning condition of the tissue. In anti-BDNF-free or anti-NeuN-free control experiments, no specific staining was observed in all sections incubated. Fluorescence in the immunostained material was assessed and images were acquired (keeping exposure times constant for each series of tissue) using a Nikon E800 epifluorescent microscope equipped with a camera (AxioCam, Zeiss). A neuron was counted only if the staining revealed a complete soma perimeter and the neuron was clearly differentiated from background.
A
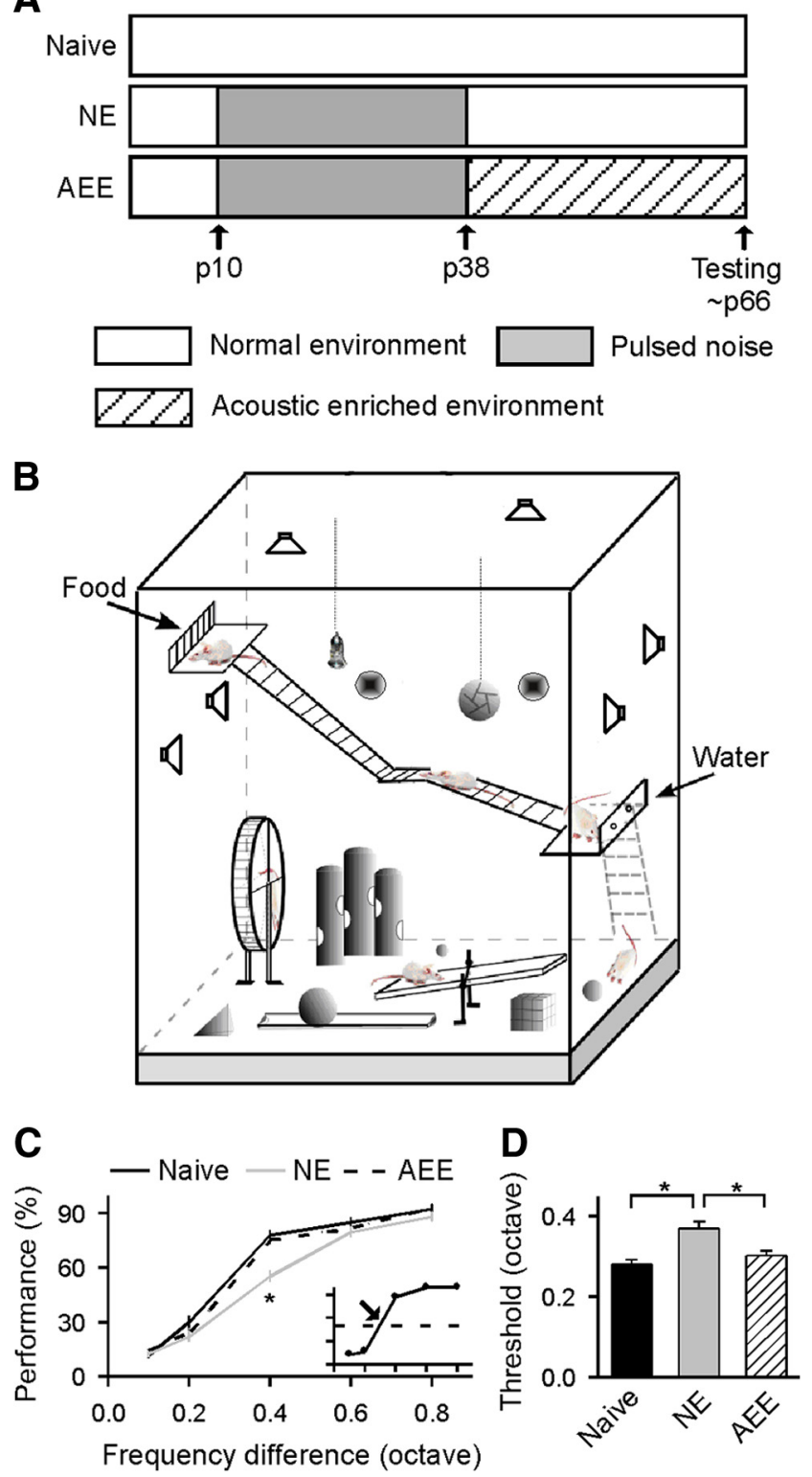

Figure 1. Behavioral performance on the frequency discrimination task. $A$, Experimental timelines for naive, NE, and AEE rats. $\boldsymbol{B}$, Schematic of enriched housing conditions. An AEE consisted of five to six rats housed in a large cage that contained a running wheel, a seesaw, balls, tunnels, cubes, cone toys, stairs, ramps, and platforms. Speakers around the cage randomly emitted pure tones with different frequencies. Three such cages were decorated in different styles and rats in each cage were switched to a different cage every 3-4 d to maintain novelty. C, Average psychometric curves obtained from naive $(N=11), \mathrm{NE}(N=10)$, and AEE $(N=11)$ rats. Error bar indicates SEM. Inset shows an example of the psychometric curve. Dashed line and arrow in the inset show $50 \%$ of maximal score and the discrimination threshold, respectively; ${ }^{*} p<0.001$. $\boldsymbol{D}$, Comparison of discrimination thresholds for the different groups; ${ }^{*} p<0.005$.

Statistical analysis. Statistical significance was assessed using unpaired $t$ test with Bonferroni correction or one-way ANOVA with post hoc Student-Newman-Keuls test. Data are presented as mean \pm SEM.

\section{Results}

\section{Sound frequency discrimination performance}

We first evaluated sound frequency discrimination performance for all three groups of rats (Fig. 1A). The behavioral examination consisted of two phases: a procedural-learning phase and a perceptual-testing phase (see Materials and Methods). In the first 
A

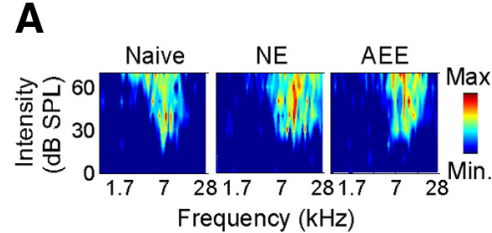

B $\square$ Naive NE $\square$ AEE
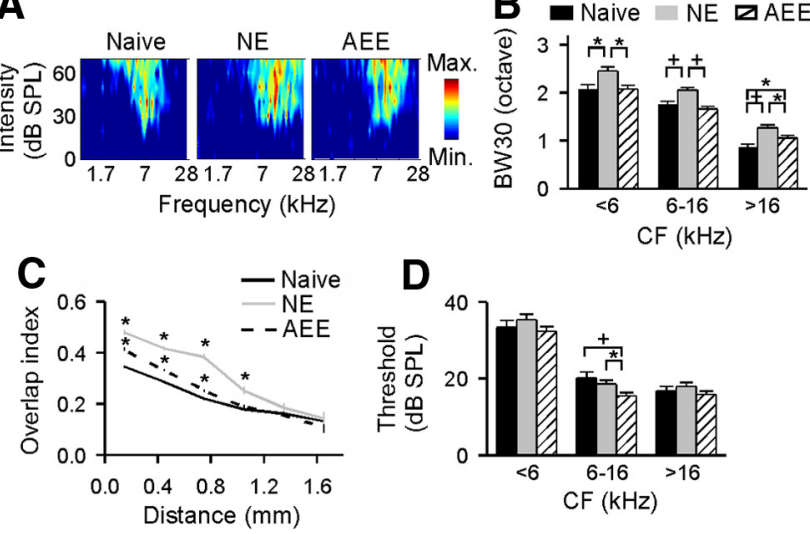

Figure 2. Cortical processing of sound frequency. $\boldsymbol{A}$, Representative examples of frequency tuning curves recorded in the cortical field $A 1$ of naive, $N E$, and $A E E$ rats, respectively. $\boldsymbol{B}$, Average receptive field bandwidths at $30 \mathrm{~dB}$ above the threshold (BW30s) for all cortical sites recorded from the different groups. Error bar indicates SEM; ${ }^{*} p<0.05$ or $+p<0.001$. C, Average tuning curve overlap index as a function of distance between recording sites; ${ }^{*} p<0.001$ compared with naive rats. $\boldsymbol{D}$, Response thresholds recorded from the different groups; ${ }^{*} p<$ 0.05 or $+p<0.01$.

phase, rats were trained to detect a large frequency difference between a target tone $(8 \mathrm{kHz})$ and a nontarget tone $(0.8$ octave separation from $8 \mathrm{kHz}$ ). After they achieved steady performance scores $(>80 \%)$, all animals from the different groups underwent the second phase of perceptual testing in which the frequency difference between target and nontarget varied from 0.8 to 0.1 octave by randomly setting the frequency of the nontarget tone in each trial. The psychometric curve then was obtained by plotting the performance score as a function of frequency difference between the target and the nontarget (Fig. $1 C$, inset). As shown in Figure $1 C$, all three groups showed high performance scores at frequency difference of 0.6 or 0.8 octave (ANOVA, both $p>0.12$ ) as it was perceptually unchallenging for these rats to discriminate such large differences between the target and the nontarget. They also had similar performance scores at a frequency difference of 0.1 octave (ANOVA, $p>0.19$ ) probably because this difference was too small to be discriminated and they all responded by chance. However, while the average performance score for NE rats at intermittent frequency difference (i.e., 0.4 octave) was significantly lower than naive rats (ANOVA with post hoc StudentNewman-Keuls test, $p<0.001$ ), that for AEE rats was comparable to naive rats (ANOVA with post hoc Student-Newman-Keuls test, $p>$ $0.05)$. As expected, the discrimination thresholds, defined as the frequency difference corresponding to a $50 \%$ performance score on the psychometric curve (Fig. 1C, inset arrow), were significantly higher for NE than for naive rats (Fig. 1D; ANOVA with post hoc Student-Newman-Keuls test, $p<0.005)$. Enriched conditions decreased the discrimination thresholds such that the values for AEE rats were now comparable to those of naive rats (ANOVA with post hoc Student-Newman-Keuls test, $p>0.05$ ). These data indicate that environmental acoustic enrichment reverses decreased frequency discrimination performance seen in $\mathrm{NE}$ rats as a result of early noise exposure.

\section{Cortical frequency selectivity}

Cortical frequency selectivity was examined by constructing frequency tuning curves for neurons in the cortical field A1 (Fig. 2A) and then measured their bandwidths $30 \mathrm{~dB}$ above the threshold (i.e., BW30s). Data were recorded from neurons in A1 from 213 sites in five naive rats, 214 sites in five NE rats, and 269 sites in six
AEE rats. No significant differences in distribution of characteristic frequencies (CFs) for these cortical sites were found among the three groups (Kruskal-Wallis test, $p>0.1$ ). Unless otherwise specified, all subsequent quantitative analyses are based on these samples.

As shown in Figure $2 B$, the frequency selectivity of cortical neurons was significantly reduced in NE rats, with larger BW30s across all frequencies tested compared with naive rats (ANOVA with post hoc Student-Newman-Keuls test, $p<0.05-0.001)$. Following $\sim 4$ weeks of housing in an enriched environment, a partial to complete recovery of the frequency selectivity (i.e., BW30) was observed. For those neurons with low or middle CFs (i.e., $<16 \mathrm{kHz}$ ), the average BW30s for AEE rats were not significantly different from those of naive rats (ANOVA with post hoc Student-Newman-Keuls test, both $p>0.05)$. Significant reductions in BW30 also were seen for high CF neurons (i.e., $>16 \mathrm{kHz}$ ), although their values still differed from naive rats (ANOVA with post hoc Student-Newman-Keuls test, $p<0.05$ ).

We next examined the similarity of frequency tuning curves recorded from neighboring cortical neurons (i.e., overlap index) to evaluate the extent of spatial activation overlap in the cortical field A1 (Fig. 2C). As expected, the average overlap indices systematically changed as a function of distance between recording sites for all three groups. The indices for NE rats, however, were significantly larger than that of naive rats at recording distances smaller than $1.2 \mathrm{~mm}$ (ANOVA with post hoc Student-NewmanKeuls test, all $p<0.001)$. Over these distances, environmental acoustic enrichment induced a highly significant reduction of the overlap index for AEE rats compared with NE rats, although values were still higher than that of naive rats (ANOVA with post hoc Student-Newman-Keuls test, all $p<0.001)$. Overlap values were not significantly different among the three groups for large $(>1.2 \mathrm{~mm}$ ) recording distances (ANOVA, both $p>0.34$ ).

It has been reported that environmental enrichment alters response thresholds of cortical neurons recorded in normal animals (Engineer et al., 2004). Here we examined that effect by comparing the data obtained from the different rat groups. As shown in Figure $2 D$, values recorded in NE rats did not significantly differ from those of naive rats (ANOVA with post hoc Student-Newman-Keuls test, all $p>0.05)$, indicating that noise exposure has little effect on response thresholds of cortical neurons (Zhang et al., 2002; Zhou and Merzenich, 2008). Response thresholds recorded in AEE rats also were comparable to those of naive rats at low and high CF ranges (ANOVA with post hoc Student-Newman-Keuls test, both $p>0.05$ ) but were lower at the middle CF range (ANOVA with post hoc Student-NewmanKeuls test, $p<0.01)$.

\section{Environmental factors contributing to cortical changes}

To evaluate contribution of various factors in enriched conditions to enrichment-induced cortical changes, we initiated the electrophysiological recording protocol in a second series of experiments conducted on $12 \mathrm{NE}$ rats. These NE rats were either reared under enriched conditions described in Figure $1 B$ but with no sound exposure (hereafter referred to as a silent enriched environment, SEE; $N=6$ ), or passively exposed to sound stimuli identical to those delivered to AEE rats in the same large cages with no decorated ingredients (hereafter referred to as a passive auditory environment, PAE; $N=6$ ). BW30s obtained from both groups then were compared with those of naive, NE, and AEE rats (Fig. 3A). As shown in Figure 3B, data recorded from SEE (recording sites $=271$ ) or PAE (recording sites $=276$ ) rats were all comparable to those of NE rats (ANOVA with post hoc Student- 

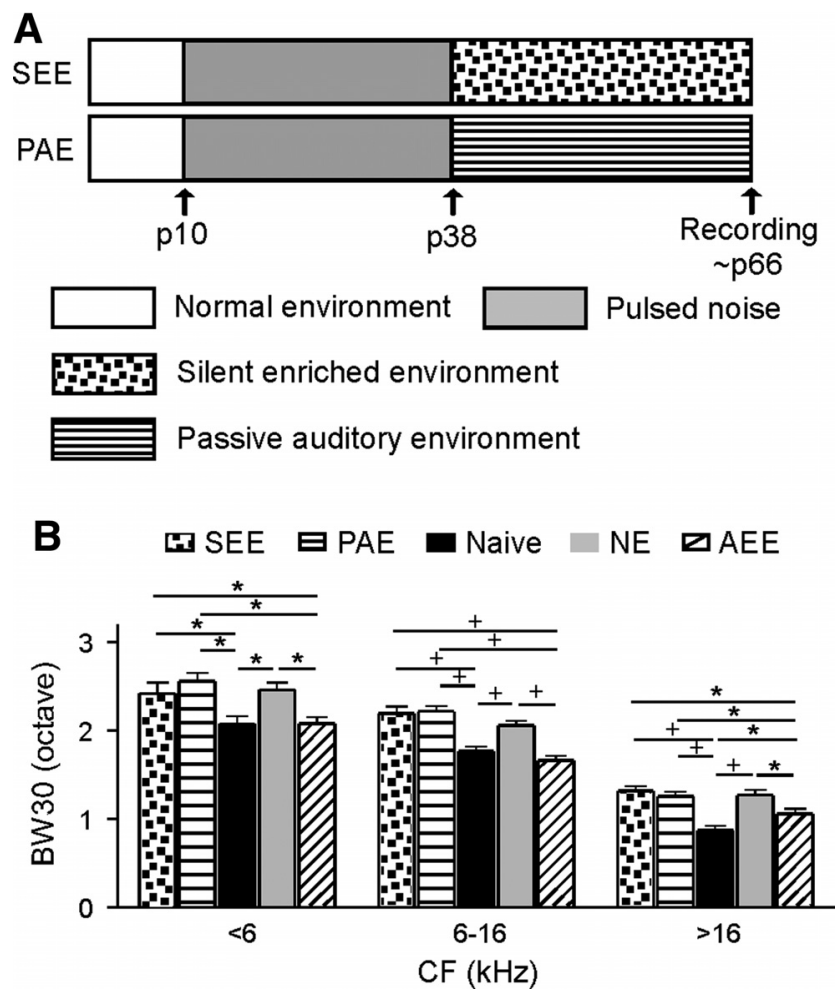

Figure 3. Environmental factors contributing to cortical changes. $A$, Experimental timelines. Note that SEE rats were reared under enriched conditions (5-6 rats per cage) described in Figure $1 B$ but with no sound stimuli. These rats were again switched to a different cage that was decorated in different styles every $3-4 \mathrm{~d}$ to maintain novelty. PAE rats were housed in the large cages with no decorated ingredients and were passively exposed to sound stimuli identical to those delivered to AEE rats. $B$, Average BW30s recorded from the different groups of rats. See also Figure $1 A$ for experimental timelines of naive, $\mathrm{NE}$, and AEE rats. Error bar indicates SEM. ${ }^{*} p<0.05$ or $+p<0.001$.

Newman-Keuls test, all $p>0.05$ ) but different from those of AEE or naive rats (ANOVA with post hoc Student-Newman-Keuls test, $p<0.05-0.001)$. This indicates that neither SEE nor PAE are sufficient to induce the cortical changes observed above.

\section{Enrichment-induced changes in adult auditory cortex}

In the data described to this point, $\mathrm{NE}$ rats were exposed to an enriched acoustic environment beginning at P38 (Fig. 1A). To examine whether enrichment would induce the same plastic changes in A1 in adult rats, five NE rats were returned to a normal housing environment for 2 months before enriched rearing beginning at P98. The BW30s of these rats measured at approximately P126 (i.e., AEE-P126 rats) then were compared with those of naive and NE rats (Fig. $4 A$ ). Consistent with our earlier studies (Zhang et al., 2002; Zhou and Merzenich, 2007), BW30s of NE rats, even recorded $\sim 3$ months after the end of noise exposure, were significantly larger than those of naive rats (Fig. 4B; ANOVA with post hoc Student-Newman-Keuls test, all $p<0.001$ ), indicating enduring effects of developmental noise exposure on cortical frequency selectivity. Enriched rearing again partially reversed the noise-induced degradation of frequency selectivity such that BW30s of AEE-P126 rats decreased significantly at each CF range when compared with NE rats (ANOVA with post hoc StudentNewman-Keuls test, all $p<0.001$ ). As a result, BW30s of AEE-P126 rats were now comparable to those of naive rats at low and high $\mathrm{CF}$ ranges (ANOVA with post hoc Student-Newman-Keuls test, both
A
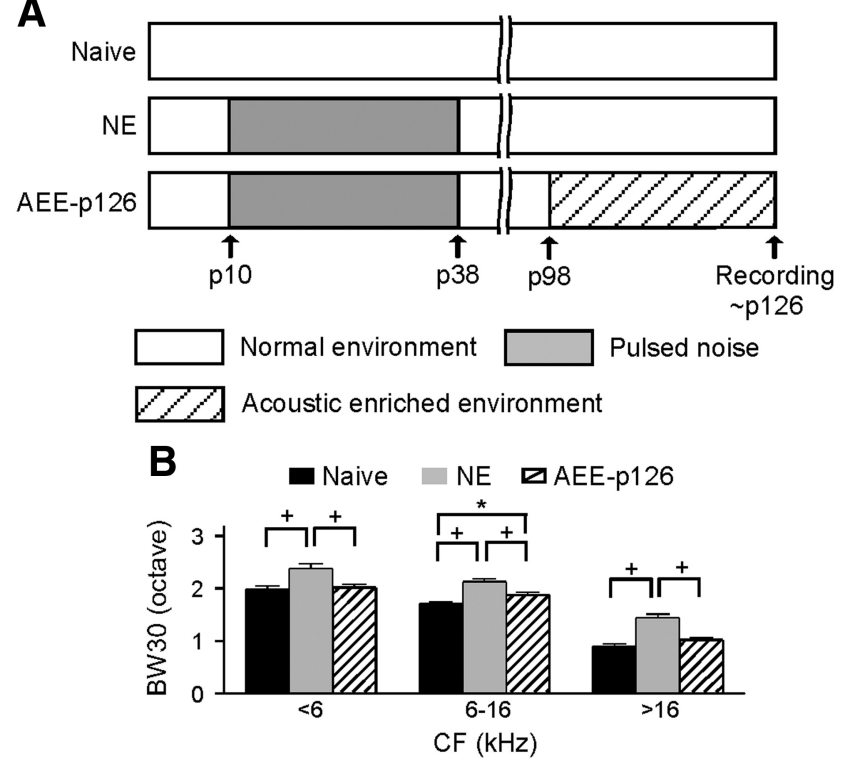

Figure 4. Enrichment-induced changes in adult auditory cortex. $\boldsymbol{A}$, Experimental timelines for naive, NE, and AEE-P126 rats. Note that AEE-P126 rats were returned to a normal auditory environment for 2 months before 4 weeks of enriched rearing. $\boldsymbol{B}$, Average BW30s for all cortical sites recorded from naive $(N=9$, recording sites $=413), \mathrm{NE}(N=5$, recording sites $=253)$, and AEE-P126 $(N=5$, recording sites $=250)$. Note that statistical analysis showed that BW30s recorded from naive rats at approximately P126 (200 sites from 4 rats) were not different from those recorded at approximately P66 (213 sites from 5 rats) at any (F range (unpaired $t$ test with Bonferroni correction, all $p>0.14$ ). These data therefore were combined as naive data here to minimize the number of animals used. Error bar indicates SEM; ${ }^{*} p<0.05$ or $+p<0.001$.

$p>0.09$ ) but still were larger at the middle CF range (ANOVA with post hoc Student-Newman-Keuls test, $p<0.05)$.

\section{LTP induced in cortical field A1}

LTP of field potentials was successfully induced in slices from all three groups of rats by TBS of the WM (Fig. $5 A$ ). As shown in Figure $5, B-D$, field potentials recorded in slices from NE rats were potentiated to an average of $139 \%$ of baseline after application of the TBS, which was significantly lower compared with data from naive rats (158\% of baseline; ANOVA with post hoc Student-Newman-Keuls test, $p<0.001)$. However, mean LTP level in AEE rats during 120 min post-TBS (153\% of baseline) was very similar to that in naive rats (ANOVA with post hoc StudentNewman-Keuls test, $p>0.05$ ), indicating that impaired LTP induced by early noise exposure was reversed by subsequent exposure to environmental acoustic enrichment.

\section{Cortical expressions of excitatory and inhibitory receptor subunits}

For the purpose of studying the molecular mechanisms responsible for reversal of impaired cortical frequency selectivity and LTP by enriched rearing, we measured expression levels of several excitatory and inhibitory receptor subunits in homogenates from auditory cortex by using Western blotting.

Multimeric NMDA receptors, including either NR2a or NR2b, have distinct biophysical properties and have been associated with different postsynaptic signaling pathways (Yashiro and Philpot, 2008). Therefore we first evaluated the possible consequence of environmental enrichment on expression levels of NR2a and NR2b subunits. We found that NE rats exhibited a significant decrease $(29.7 \pm 14.4 \%)$ in the NR2a expression level compared with naive rats (Fig. 6A, left; ANOVA with post hoc 

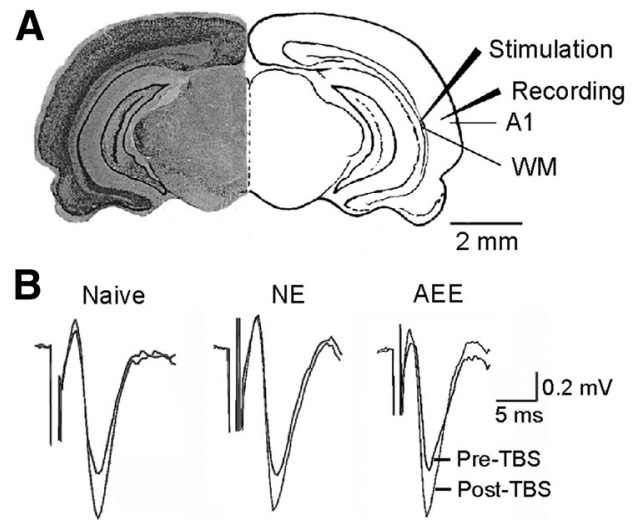

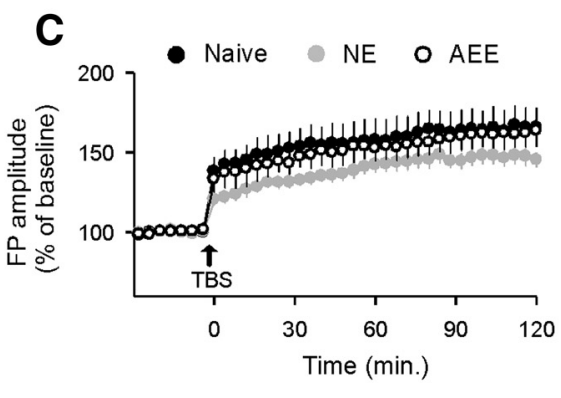

D

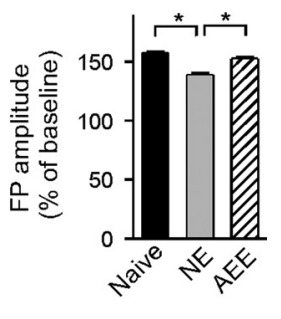

Figure 5. LTP recorded in the cortical field A1. A, Image of a coronal section through the whole brain with a superimposed schematic of stimulation and recording configuration in A1. B, Sample field potentials (FPs) evoked before (pre-) and after (post-) the TBS for naive, NE, and AEE rats. See Figure $1 A$ for experimental timelines of the different groups. $C$, Time courses of LTPs in naive ( $n=$ 10), NE $(n=10)$, and AEE $(n=10)$ rats. Error bar indicates SEM. D, Average FP amplitudes (percentage of baseline) in the different groups. ${ }^{*} p<0.001$.
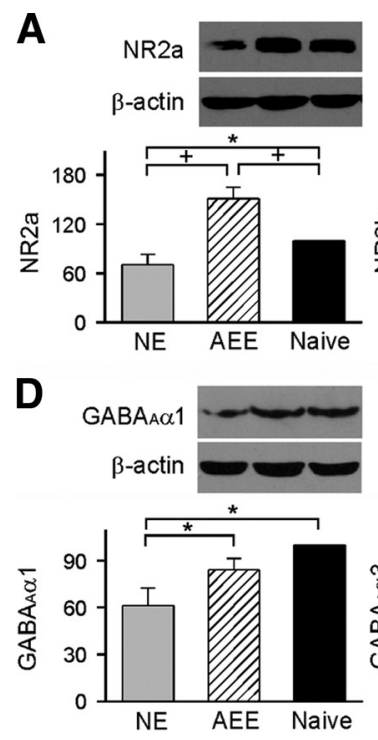
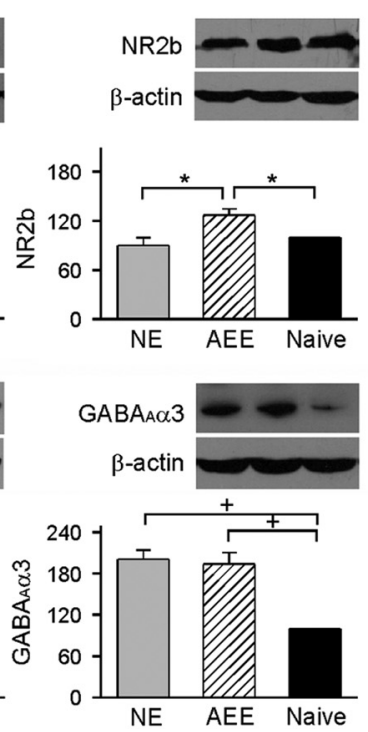

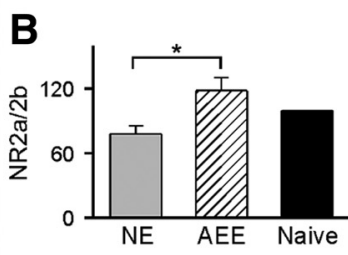

C

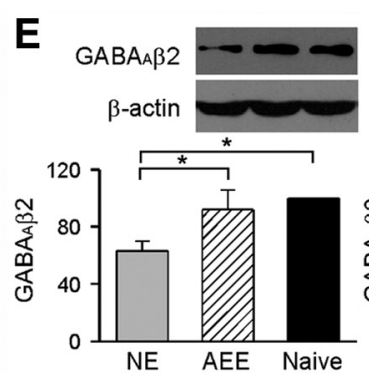

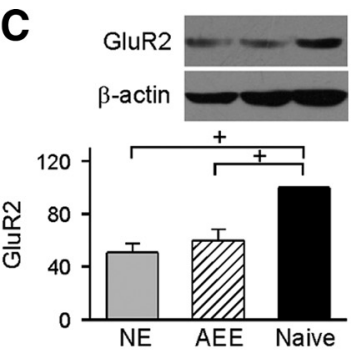

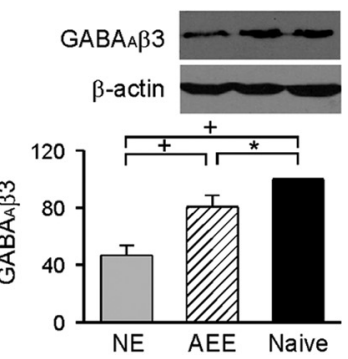

Figure 6. Cortical expressions of the excitatory and inhibitory receptor subunits. $A$, Expression levels of the NMDA NR2a (left) and NR2b (right) subunits in NE $(N=6), A E E(N=6)$, and naive $(N=6)$ rats. The insets show representative Western blots. See Figure $1 A$ for experimental timelines of the different groups. Error bar indicates $S E M ; ~ *{ }^{*} p<0.05$ or $+p<0.01$. $\boldsymbol{B}$, The NR2a/2b ratio for the different groups. C, Expression levels of the AMPA GluR2 subunit. $\boldsymbol{D}$, Expression levels of the $\mathrm{GABA}_{A} \alpha 1$ (left) and $\alpha 3$ (right) subunits. E, Expression levels of the GABA ${ }_{A} \beta 2$ (left) and $\beta 3$ (right) subunits.

Student-Newman-Keuls test, $p<0.05)$. While the expression level of NR2b in NE rats also was lower $(9.8 \pm 8.3 \%)$ than naive rats, the difference did not reach statistical significance (Fig. $6 \mathrm{~A}$, right; ANOVA with post hoc Student-Newman-Keuls test, $p>$ $0.05)$. Therefore the ratio of NR2a/2b also slightly decreased for $\mathrm{NE}$ rats compared with naive rats with no statistical significance (Fig. 6B; ANOVA with post hoc Student-Newman-Keuls test, $p>$ $0.05)$. Expression levels of both NR2a and NR2b were significantly higher in AEE compared with naive rats $(51.4 \pm 15.3 \%$ higher than naive rats for NR2a and $26.8 \pm 11.4 \%$ higher than naive rats for NR2b; ANOVA with post hoc Student-NewmanKeuls test, $p<0.05-0.01$ ). These different changes in NR2a and NR2b resulted in a shift in the NR2a/NR2b ratio, which was significantly higher in AEE compared with NE rats (Fig. 6B; ANOVA with post hoc Student-Newman-Keuls test, $p<0.05$ ) but was comparable to that of naive rats (ANOVA with post hoc Student-Newman-Keuls test, $p>0.05$ ).

The expression level of cortical GluR2 subunit also was examined for the different groups of rats. We found that NE rats exhibited lower expression levels compared with naive rats (Fig. 6C;
ANOVA with post hoc Student-Newman-Keuls test, $p<0.01$ ). No significant difference in the expression level of GluR2, however, was found between NE and AEE rats (ANOVA with post hoc Student-Newman-Keuls test, $p>0.05)$. Thus, downregulated GluR2 expression as a result of early noise exposure was not reversed by subsequent enriched rearing.

We last examined cortical expression levels of $\mathrm{GABA}_{\mathrm{A}} \alpha 1, \alpha 3$, $\beta 2$, and $\beta 3$ subunits. As shown in Figure $6 D$, left, the expression level of $\alpha 1$ was significantly lower in NE compared with naive rats (ANOVA with post hoc Student-Newman-Keuls test, $p<0.05$ ). Enriched conditions increased downregulated $\alpha 1$ expression such that the $\alpha 1$ level in AEE rats, although still slightly lower, was not statistically different from that of naive rats (ANOVA with post hoc Student-Newman-Keuls test, $p>0.05$ ). Conversely, early noise exposure significantly increased $\alpha 3$ expression $(\sim 2$ fold) compared with naive rats (Fig. $6 D$, right; ANOVA with post hoc Student-Newman-Keuls test, $p<0.01$ ). This effect was not reversed by environmental acoustic enrichment as the $\alpha 3$ level of AEE rats still was comparable to that of NE rats (ANOVA with post hoc Student-Newman-Keuls test, $p>0.05$ ) but higher than 
that of naive rats (ANOVA with post hoc Student-Newman-Keuls test, $p<0.01$ ). Moreover, expression levels of $\beta 2$ and $\beta 3$ for NE rats were both lower than those of naive rats (Fig. 6E; ANOVA with post hoc Student-Newman-Keuls test, $p<0.05-$ $0.01)$. These noise-induced expression changes in both subunits also were partially reversed after enriched rearing such that the level of $\beta 2$ for AEE rats was similar to that of naive rats (Fig. 6E, left; ANOVA with post hoc Student-NewmanKeuls test, $p>0.05)$. The expression level of $\beta 3$ for AEE rats also was significantly increased compared with NE rats (Fig. $6 E$, right; ANOVA with post hoc StudentNewman-Keuls test, $p<0.01$ ), although the value still was statistically lower than that of naive rats (ANOVA with post hoc Student-Newman-Keuls test, $p<0.05$ ).

\section{Cortical BDNF expression}

We further quantified the expression level of cortical BDNF, which has been shown to contribute to the regulation of plasticity in the sensory cortex (Sale et al., 2009; Tognini et al., 2012; Zhou and Merzenich, 2012). Immunohistochemistry analysis revealed significant decreases in the density of BDNF-immunostained (BDNF+) neurons of NE rats compared with naive rats across cortical layers II/III-V (Fig. $7 B$ vs $A, D$; ANOVA with post hoc Student-Newman-Keuls test, $p<0.05-0.01)$. Enriched conditions reversed these differences such that the density of BDNF+ neurons in AEE rats was comparable to that of naive rats across these cortical layers (Fig. 7C vs $A, D$; ANOVA with post hoc Student-NewmanKeuls test, all $p>0.05)$. Note that the density of BDNF+ neurons in cortical layer VI was comparable among all three groups (ANOVA, $p=0.4$ ). In addition, cortical neuron density as shown by NeuN staining was not different among the three groups (Fig. $7 E-H$; ANOVA, all $p>0.1$ ).

\section{Discussion}

Consistent with the results of previous studies, early disrupted acoustic inputs (noise exposure) degraded frequency selectivity of neurons in the cortical field A1 (Zhang et al., 2002; Zhou and Merzenich, 2007, 2008; Insanally et al., 2010). The observation of nearly normal response selectivity in A1 of AEE rats in the current study indicates that AEE reverses the cortical deficits in frequency processing caused by early exposure to pulsed noise (Zhou and Merzenich, 2008). It has been compellingly argued that decreased cortical response selectivity degrades the neurological encoding of the details of acoustic inputs, thereby impairing auditory-related perceptual abilities (Paterson et al., 2006; Zhou and Merzenich, 2012; Anderson et al., 2013). It thus is conceivable that cortical deficits at least account partially for poor frequency discrimination seen in NE rats. This idea is further strengthened by positive changes in behavioral performance of AEE rats with reversal of cortical frequency selectivity and response synchronization following environmental acoustic enrichment.

It should be noted that recent human studies have shown that acoustic experience either facilitates or impairs neurophysiological representation of sound in the subcortical structures within the auditory pathway, which, consequently, can influence language development and reading abilities (Kraus and Chandrasek-
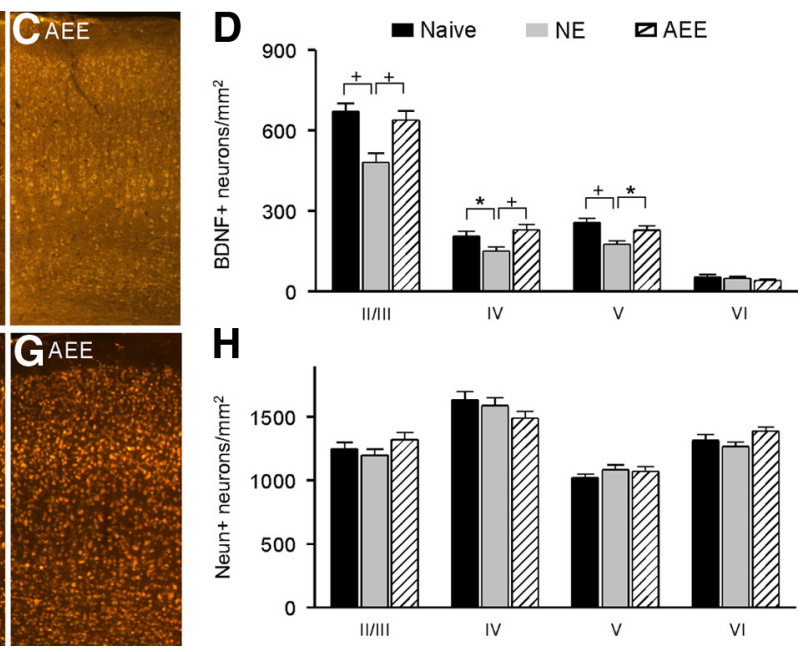

Figure 7. Cortical BDNF expression. $\boldsymbol{A}-\boldsymbol{C}$, Photomicrographs of BDNF + cortical sections for naive $(\boldsymbol{A}), \mathrm{NE}(\boldsymbol{B})$, and $\mathrm{AEE}(\boldsymbol{C})$ rats. Photomicrographs of NeuN + cortical sections for naive $(\boldsymbol{E}), \mathrm{NE}(\boldsymbol{F})$, and AEE $(\boldsymbol{G})$ rats. Cortical layers are indicated in $\boldsymbol{E}$. Scale bar, 200 ( 8 hemispheres), NE ( 8 hemispheres), and AEE ( 8 hemispheres) rats.

aran, 2010; Hornickel et al., 2011; Hornickel and Kraus, 2013; Skoe et al., 2013). In animal studies, environment-dependent alteration of spectral selectivity and reorganization of the tonotopic map have been documented in the midbrain of mice (Sanes and Constantine-Paton, 1983, 1985; Yu et al., 2007) and rats (Poon and Chen, 1992). It is also conceivable that AEE-induced changes in cortical molecular expression patterns observed in the current study might be happening in subcortical sites as well. Therefore whether enriched environment also refines subcortical processing of sound and thus improves the frequency discrimination performance seen in AEE rats needs further study. In addition, the behavioral task applied in this study has significant memory and discrimination components as it requires animals to identify a fixed, remembered target auditory stimulus from a set of distracter stimuli. It has been demonstrated in experiments using radial maze and Morris water maze that enriched conditions can improve learning and memory abilities in rodents (Gardner et al., 1975; Williams et al., 2001). We therefore cannot exclude the possibility that changes in the function of learning and memory following enriched rearing also contribute to the observed recovery from behavioral deficits in AEE rats. Last, it would be of interest to further examine the auditory discrimination abilities of these AEE rats in noisy backgrounds (Shetake et al., 2011; Strait et al., 2013) since earlier studies have shown that speech-in-noise perception abilities of those children with learning disabilities were more adversely affected by a decreasing signal-to-noise ratio (Cunningham et al., 2001; Bradlow et al., 2003).

Environmental enrichment as an experimental protocol usually consists of a combination of enhanced social interactions, sensory-motor activity, and exploratory behavior. In this study sound exposure also was added to the paradigm as in our earlier studies (Cai et al., 2009, 2010). Given the complexity of enriched environments, it is possible that many environmental factors contribute to the observed changes in cortical responses. For example, both social experience and physical exercise have been shown to stimulate anatomical and neurochemical changes that are similar to those induced by complete environmental enrichment (Renner and Rosenzweig, 1986; van Praag et al., 1999; 
Risedal et al., 2002). Each factor, however, presumably induces plasticity only in brain regions associated with social relations or exercise and thus is not sufficient to stimulate plasticity in the auditory cortex (Percaccio et al., 2007). This hypothesis is further strengthened by our observation that neither enriched conditions excluding passive sound exposure nor sound exposure itself affects frequency selectivity of neurons in A1. Alternatively, environmental acoustic enrichment (i.e., sound exposure under enriched conditions) has been shown to induce profound cortical plasticity (Percaccio et al., 2007 and current studies). All these results highlight the critical role of acoustic inputs in regulating enrichment-induced plasticity in the auditory cortex. Additional studies will be needed to determine how specific environmental factors (particularly the sound stimulation) influence cortical plasticity observed in this study.

To date neurochemical mechanisms underlying enrichmentinduced cortical plasticity are not well understood. However, it has been implicated that changes in NMDA and GABA receptor expression levels are involved in enrichment-dependent remediation of neural function and plasticity (Nichols et al., 2007; Sale et al., 2007; Cai et al., 2010; Mainardi et al., 2010; Alwis and Rajan, 2013). Indeed, our recent studies have shown that enrichment exposure of juvenile rats alters protein expression levels of certain NMDA receptor subunits (NR2a and NR2b) and $\mathrm{GABA}_{\mathrm{A}}$ receptor subunits ( $\alpha 1$ and $\beta 3$ ) in the auditory cortex (Cai et al., 2010). Environmental enrichment also has been shown to selectively enhance excitatory glutamatergic transmission in layer II/III of the auditory cortex (Nichols et al., 2007) and potentiate synaptic strength and plasticity of the thalamocortical pathway by altering glutamatergic and GABAergic neurotransmission in the visual cortex (Mainardi et al., 2010). In this study, we observed a larger decrease in the expression level for NR2a than for NR2b, and thus a decreased NR2a/2b ratio in A1 as a consequence of noise exposure. The following enriched rearing significantly enhanced expressions of both subunits and restored their ratio to the normal level of naive rats. In addition, noise-induced downregulation of $\mathrm{GABA}_{\mathrm{A}} \alpha 1, \beta 2$, and $\beta 3$ subunits also was reversed after enriched rearing. Many previous studies have shown that the balance of cortical excitation/inhibition plays an important role in shaping neuronal processing (Wang et al., 2000; Rubenstein and Merzenich, 2003; Wehr and Zador, 2003; Benali et al., 2008; Wu et al., 2008). Degraded frequency tuning of cortical neurons seen in NE rats is similar to that resulting from reduced cortical GABAergic inhibition (Wang et al., 2000; Caspary et al., 2008). The current results thus indicate that enriched conditions re-establish cortical frequency selectivity presumably through restoring the proper expression profile of certain excitatory and inhibitory neurotransmitter receptors (for instance, those containing NR2a and $2 \mathrm{~b}, \alpha 1, \beta 2$, and $\beta 3$ subunits as shown in the present study).

We found that downregulated GluR2 and upregulated $\mathrm{GABA}_{\mathrm{A}} \alpha 3$ induced by early noise exposure did not change after 4 weeks of environmental acoustic enrichment. These findings indicate that enriched conditions have little effect on expressions of these two receptor subunits in developmentally impaired A1. Further studies clearly are needed to characterize roles of both receptor subunits on regulation of enrichment-induced plasticity in the auditory cortex.

Many studies have supported the hypothesis that changes in synaptic efficacy, including LTP, are associated with experiencedependent plasticity in the adult sensory cortex (Rioult-Pedotti et al., 2000; Whitlock et al., 2006; Sale et al., 2007; Hager and Dringenberg, 2010; Gagolewicz and Dringenberg, 2011; Zhang et al., 2013). For example, previous studies have shown that changing the NMDA receptor subunit composition shifts LTP threshold, thereby influencing experience-dependent modifications in neuronal circuitry (Yashiro and Philpot, 2008; Gagolewicz and Dringenberg, 2011; Zhang et al., 2013). While not all induced forms of LTP are NMDA-dependent, the NMDA antagonist has been shown to block LTP induction in the auditory cortex (Kudoh and Shibuki, 1994; Fujisaki et al., 1995). Chronic implantation of Elvax containing an NMDA antagonist during the critical period decreases LTP in auditory cortical slices of adult mice but application of NMDA to Elvax-treated cortex restores the LTP magnitude. This indicates that NMDA receptor activation can reverse the effect of chronic treatment with its antagonist (Mao et al., 2006). Massey et al. (2004) also reported that the induction of LTP in adult cortex required the activation of NR2a-containing NMDA receptors. The association of enhanced LTP with increased NR2a/2b ratio following enriched rearing in current studies again suggests an important role of NMDA receptor subunit composition in regulating the magnitude and/or threshold of TBS-evoked LTP in the adult A1. Additionally, we found that degraded expression of cortical BDNF in NE rats was reversed following environmental acoustic enrichment. Accumulating evidence from recent studies suggests that BDNF also is involved in regulating the synaptic plasticity or LTP in both developing and adult sensory cortices through activity-dependent modulation of synaptic connections (Akaneya et al., 1997; Huang and Reichardt, 2001; Sale et al., 2007, 2009; Maya Vetencourt et al., 2008; Bracken and Turrigiano, 2009). Application of BDNF, for example, has been shown to enhance the magnitude of LTP induced by tetanic stimulation of the layer IV in the developing visual cortex (Akaneya et al., 1997). Upregulation of BDNF expression in adult visual cortex by antidepressant fluoxetine also reinstates LTP as well as ocular dominance plasticity (Maya Vetencourt et al., 2008).Together, these results suggest that environmental acoustic enrichment restores impaired LTP in NE rats probably by upregulating expressions of NMDA receptor subunits (particularly the NR2a/2b ratio) and BDNF, leading to normalization of cortical auditory dysfunction.

In conclusion, we demonstrate that environmental acoustic enrichment nearly restores to normal the degraded behavioral and cortical neuronal processing of sound frequency resulting from early disrupted acoustic inputs. The observed behavioral and physiological effects induced by enrichment were accompanied by recovery of cortical expressions of certain NMDA and $\mathrm{GABA}_{\mathrm{A}}$ receptor subunits and BDNF. These molecular changes presumably enhance the efficiency of cortical synaptic transmission and thereby promote recovery from developmentally induced auditory cortical dysfunction. Further study of the underlying mechanisms would bear great practical and theoretical importance for normalizing neurological function from pathologies that cause hearing and associated language impairments in older children and adults.

\section{References}

Ahissar E, Nagarajan S, Ahissar M, Protopapas A, Mahncke H, Merzenich MM (2001) Speech comprehension is correlated with temporal response patterns recorded from auditory cortex. Proc Natl Acad Sci U S A 98:13367-13372. CrossRef Medline

Akaneya Y, Tsumoto T, Kinoshita S, Hatanaka H (1997) Brain-derived neurotrophic factor enhances long-term potentiation in rat visual cortex. J Neurosci 17:6707-6716. Medline

Alwis DS, Rajan R (2013) Environmental enrichment causes a global potentiation of neuronal responses across stimulus complexity and lamina of sensory cortex. Front Cell Neurosci 7:124. CrossRef Medline

Anderson S, White-Schwoch T, Parbery-Clark A, Kraus N (2013) Reversal 
of age-related neural timing delays with training. Proc Natl Acad Sci U S A 110:4357-4362. CrossRef Medline

Baldini S, Restani L, Baroncelli L, Coltelli M, Franco R, Cenni MC, Maffei L, Berardi N (2013) Enriched early life experiences reduce adult anxietylike behavior in rats: a role for insulin-like growth factor 1. J Neurosci 33:11715-11723. CrossRef Medline

Bartoletti A, Medini P, Berardi N, Maffei L (2004) Environmental enrichment prevents effects of dark-rearing in the rat visual cortex. Nat Neurosci 7:215-216. CrossRef Medline

Beaulieu C, Cynader M (1990) Effect of the richness of the environment on neurons in cat visual cortex. I. Receptive field properties. Brain Res Dev Brain Res 53:71-81. CrossRef Medline

Benali A, Weiler E, Benali Y, Dinse HR, Eysel UT (2008) Excitation and inhibition jointly regulate cortical reorganization in adult rats. J Neurosci 28:12284-12293. CrossRef Medline

Bose M, Muñoz-Llancao P, Roychowdhury S, Nichols JA, Jakkamsetti V, Porter B, Byrapureddy R, Salgado H, Kilgard MP, Aboitiz F, DagninoSubiabre A, Atzori M (2010) Effect of the environment on the dendritic morphology of the rat auditory cortex. Synapse 64:97-110. CrossRef Medline

Bracken BK, Turrigiano GG (2009) Experience-dependent regulation of TrkB isoforms in rodent visual cortex. Dev Neurobiol 69:267-278. CrossRef Medline

Bradlow AR, Kraus N, Hayes E (2003) Speaking clearly for children with learning disabilities: sentence perception in noise. J Speech Lang Hear Res 46:80-97. CrossRef Medline

Cai R, Guo F, Zhang J, Xu J, Cui Y, Sun X (2009) Environmental enrichment improves behavioral performance and auditory spatial representation of primary auditory cortical neurons in rat. Neurobiol Learn Mem 91:366376. CrossRef Medline

Cai R, Zhou X, Guo F, Xu J, Zhang J, Sun X (2010) Maintenance of enriched environment induced changes of auditory spatial sensitivity and expression of GABAA, NMDA, and AMPA receptor subunits in rat auditory cortex. Neurobiol Learn Mem 94:452-460. CrossRef Medline

Caspary DM, Ling L, Turner JG, Hughes LF (2008) Inhibitory neurotransmission, plasticity and aging in the mammalian central auditory system. J Exp Biol 211:1781-1791. CrossRef Medline

Coq JO, Xerri C (1998) Environmental enrichment alters organizational features of the forepaw representation in the primary somatosensory cortex of adult rats. Exp Brain Res 121:191-204. CrossRef Medline

Cunningham J, Nicol T, Zecker SG, Bradlow A, Kraus N (2001) Neurobiologic responses to speech in noise in children with learning problems: deficits and strategies for improvement. Clin Neurophysiol 112:758-767. CrossRef Medline

Del Arco A, Segovia G, Garrido P, de Blas M, Mora F (2007) Stress, prefrontal cortex and environmental enrichment: studies on dopamine and acetylcholine release and working memory performance in rats. Behav Brain Res 176:267-273. CrossRef Medline

de Villers-Sidani E, Alzghoul L, Zhou X, Simpson KL, Lin RC, Merzenich MM (2010) Recovery of functional and structural age-related changes in the rat primary auditory cortex with operant training. Proc Natl Acad Sci U S A 107:13900-13905. CrossRef Medline

Dhanushkodi A, Bindu B, Raju TR, Kutty BM (2007) Exposure to enriched environment improves spatial learning performances and enhances cell density but not choline acetyltransferase activity in the hippocampus of ventral subicular-lesioned rats. Behav Neurosci 121:491-500. CrossRef Medline

Dinse HR (2004) Sound case for enrichment. Focus on "environmental enrichment improves response strength, threshold, selectivity, and latency of auditory cortex neurons". J Neurophysiol 92:36-37. CrossRef Medline

Engineer ND, Percaccio CR, Pandya PK, Moucha R, Rathbun DL, Kilgard MP (2004) Environmental enrichment improves response strength, threshold, selectivity, and latency of auditory cortex neurons. J Neurophysiol 92:73-82. CrossRef Medline

Fujisaki T, Kudoh M, Shibuki K (1995) Functional brain block preparation of the rat auditory cortex. Neurosci Res 23:321-326. CrossRef Medline

Gagolewicz PJ, Dringenberg HC (2011) NR2B-subunit dependent facilitation of long-term potentiation in primary visual cortex following visual discrimination training of adult rats. Eur J Neurosci 34:1222-1229. CrossRef Medline

Gardner EB, Boitano JJ, Mancino NS, D’Amico DP (1975) Environmental enrichment and deprivation: effects on learning, memory and exploration. Physiol Behav 14:321-327. CrossRef Medline

Guo F, Zhang J, Zhu X, Cai R, Zhou X, Sun X (2012) Auditory discrimination training rescues developmentally degraded directional selectivity and restores mature expression of GABAA and AMPA receptor subunits in rat auditory cortex. Behav Brain Res 229:301-307. CrossRef Medline

Hager AM, Dringenberg HC (2010) Training-induced plasticity in the visual cortex of adult rats following visual discrimination learning. Learn Mem 17:394-401. CrossRef Medline

Hornickel J, Kraus N (2013) Unstable representation of sound: a biological marker of dyslexia. J Neurosci 33:3500-3504. CrossRef Medline

Hornickel J, Chandrasekaran B, Zecker S, Kraus N (2011) Auditory brainstem measures predict reading and speech-in-noise perception in schoolaged children. Behav Brain Res 216:597-605. CrossRef Medline

Huang EJ, Reichardt LF (2001) Neurotrophins: roles in neuronal development and function. Annu Rev Neurosci 24:677-736. CrossRef Medline

Insanally MN, Albanna BF, Bao S (2010) Pulsed noise experience disrupts complex sound representations. J Neurophysiol 103:2611-2617. CrossRef Medline

Jakkamsetti V, Chang KQ, Kilgard MP (2012) Reorganization in processing of spectral and temporal input in the rat posterior auditory field induced by environmental enrichment. J Neurophysiol 107:1457-1475. CrossRef Medline

Kilgard MP, Vazquez JL, Engineer ND, Pandya PK (2007) Experience dependent plasticity alters cortical synchronization. Hear Res 229:171-179. CrossRef Medline

Komitova M, Xenos D, Salmaso N, May Tran KM, Brand T, Schwartz ML, Ment L, Vaccarino FM (2013) Hypoxia-induced developmental delays of inhibitory interneurons are reversed by environmental enrichment in the postnatal mouse forebrain. J Neurosci 33:13375-13387. CrossRef Medline

Kraus N, Chandrasekaran B (2010) Music training for the development of auditory skills. Nat Rev Neurosci 11:599-605. CrossRef Medline

Kudoh M, Shibuki K (1994) Long-term potentiation in the auditory cortex of adult rats. Neurosci Lett 171:21-23. CrossRef Medline

Leggio MG, Mandolesi L, Federico F, Spirito F, Ricci B, Gelfo F, Petrosini L (2005) Environmental enrichment promotes improved spatial abilities and enhanced dendritic growth in the rat. Behav Brain Res 163:78-90. CrossRef Medline

Mainardi M, Landi S, Gianfranceschi L, Baldini S, De Pasquale R, Berardi N, Maffei L, Caleo M (2010) Environmental enrichment potentiates thalamocortical transmission and plasticity in the adult rat visual cortex. J Neurosci Res 88:3048-3059. CrossRef Medline

Mao Y, Zang S, Zhang J, Sun X (2006) Early chronic blockade of NR2B subunits and transient activation of NMDA receptors modulate LTP in mouse auditory cortex. Brain Res 1073-1074:131-138.

Massey PV, Johnson BE, Moult PR, Auberson YP, Brown MW, Molnar E, Collingridge GL, Bashir ZI (2004) Differential roles of NR2A and NR2B-containing NMDA receptors in cortical long-term potentiation and long-term depression. J Neurosci 24:7821-7828. CrossRef Medline

Maya Vetencourt JF, Sale A, Viegi A, Baroncelli L, De Pasquale R, O'Leary OF, Castrén E, Maffei L (2008) The antidepressant fluoxetine restores plasticity in the adult visual cortex. Science 320:385-388. CrossRef Medline

Nagarajan S, Mahncke H, Salz T, Tallal P, Roberts T, Merzenich MM (1999) Cortical auditory signal processing in poor readers. Proc Natl Acad Sci U S A 96:6483-6488. CrossRef Medline

Nichols JA, Jakkamsetti VP, Salgado H, Dinh L, Kilgard MP, Atzori M (2007) Environmental enrichment selectively increases glutamatergic responses in layer II/III of the auditory cortex of the rat. Neuroscience 145:832-840. CrossRef Medline

Pan Y, Zhang J, Cai R, Zhou X, Sun X (2011) Developmentally degraded directional selectivity of the auditory cortex can be restored by auditory discrimination training in adults. Behav Brain Res 225:596-602. CrossRef Medline

Paterson SJ, Heim S, Friedman JT, Choudhury N, Benasich AA (2006) Development of structure and function in the infant brain: implications for cognition, language and social behaviour. Neurosci Biobehav Rev 30: 1087-1105. CrossRef Medline

Paxinos G, Watson C (1998) The rat brain in stereotaxic coordinate. New York: Academic.

Percaccio CR, Engineer ND, Pruette AL, Pandya PK, Moucha R, Rathbun DL, Kilgard MP (2005) Environmental enrichment increases paired-pulse 
depression in rat auditory cortex. J Neurophysiol 94:3590-3600. CrossRef Medline

Percaccio CR, Pruette AL, Mistry ST, Chen YH, Kilgard MP (2007) Sensory experience determines enrichment-induced plasticity in rat auditory cortex. Brain Res 1174:76-91. CrossRef Medline

Polley DB, Steinberg EE, Merzenich MM (2006) Perceptual learning directs auditory cortical map reorganization through top-down influences. J Neurosci 26:4970-4982. CrossRef Medline

Polley DB, Read HL, Storace DA, Merzenich MM (2007) Multiparametric auditory receptive field organization across five cortical fields in the albino rat. J Neurophysiol 97:3621-3638. CrossRef Medline

Poon PW, Chen X (1992) Postnatal exposure to tones alters the tuning characteristics of inferior collicular neurons in the rat. Brain Res 585:391-394. CrossRef Medline

Profant O, Burianová J, Syka J (2013) The response properties of neurons in different fields of the auditory cortex in the rat. Hear Res 296:51-59. CrossRef Medline

Rampon C, Tang YP, Goodhouse J, Shimizu E, Kyin M, Tsien JZ (2000) Enrichment induces structural changes and recovery from nonspatial memory deficits in CA1 NMDAR1-knockout mice. Nat Neurosci 3:238244. CrossRef Medline

Renner MJ, Rosenzweig MR (1986) Social interactions among rats housed in grouped and enriched conditions. Dev Psychobiol 19:303-313. CrossRef Medline

Rioult-Pedotti MS, Friedman D, Donoghue JP (2000) Learning-induced LTP in neocortex. Science 290:533-536. CrossRef Medline

Risedal A, Mattsson B, Dahlqvist P, Nordborg C, Olsson T, Johansson BB (2002) Environmental influences on functional outcome after a cortical infarct in the rat. Brain Res Bull 58:315-321. CrossRef Medline

Rubenstein JL, Merzenich MM (2003) Model of autism: increased ratio of excitation/inhibition in key neural systems. Genes Brain Behav 2:255267. CrossRef Medline

Sale A, Maya Vetencourt JF, Medini P, Cenni MC, Baroncelli L, De Pasquale R, Maffei L (2007) Environmental enrichment in adulthood promotes amblyopia recovery through a reduction of intracortical inhibition. Nat Neurosci 10:679-681. CrossRef Medline

Sale A, Berardi N, Maffei L (2009) Enrich the environment to empower the brain. Trends Neurosci 32:233-239. CrossRef Medline

Sanes DH, Bao S (2009) Tuning up the developing auditory CNS. Curr Opin Neurobiol 19:188-199. CrossRef Medline

Sanes DH, Constantine-Paton M (1983) Altered activity patterns during development reduce neural tuning. Science 221:1183-1185. CrossRef Medline

Sanes DH, Constantine-Paton M (1985) The sharpening of frequency tuning curves requires patterned activity during development in the mouse, Mus musculus. J Neurosci 5:1152-1166. Medline

Schreiner CE, Polley DB (2014) Auditory map plasticity: diversity in causes and consequences. Curr Opin Neurobiol 24C:143-156. CrossRef Medline

Shetake JA, Wolf JT, Cheung RJ, Engineer CT, Ram SK, Kilgard MP (2011) Cortical activity patterns predict robust speech discrimination ability in noise. Eur J Neurosci 34:1823-1838. CrossRef Medline

Skoe E, Krizman J, Kraus N (2013) The impoverished brain: disparities in maternal education affect the neural response to sound. J Neurosci 33: 17221-17231. CrossRef Medline

Strait DL, Parbery-Clark A, O'Connell S, Kraus N (2013) Biological impact of preschool music classes on processing speech in noise. Dev Cogn Neurosci 6:51-60. CrossRef Medline

Tognini P, Manno I, Bonaccorsi J, Cenni MC, Sale A, Maffei L (2012) Envi- ronmental enrichment promotes plasticity and visual acuity recovery in adult monocular amblyopic rats. PLoS One 7:e34815. CrossRef

van Praag H, Kempermann G, Gage FH (1999) Running increases cell proliferation and neurogenesis in the adult mouse dentate gyrus. Nat Neurosci 2:266-270. CrossRef Medline

van Praag H, Kempermann G, Gage FH (2000) Neural consequences of environmental enrichment. Nat Rev Neurosci 1:191-198. Medline

Van Waas M, Soffié M (1996) Differential environmental modulations on locomotor activity, exploration and spatial behaviour in young and old rats. Physiol Behav 59:265-271. CrossRef Medline

Wang BS, Feng L, Liu M, Liu X, Cang J (2013) Environmental enrichment rescues binocular matching of orientation preference in mice that have a precocious critical period. Neuron 80:198-209. CrossRef Medline

Wang J, Caspary D, Salvi RJ (2000) GABA-A antagonist causes dramatic expansion of tuning in primary auditory cortex. Neuroreport 11:11371140. CrossRef Medline

Wehr M, Zador AM (2003) Balanced inhibition underlies tuning and sharpens spike timing in auditory cortex. Nature 426:442-446. CrossRef Medline

Whitlock JR, Heynen AJ, Shuler MG, Bear MF (2006) Learning induces long-term potentiation in the hippocampus. Science 313:1093-1097. CrossRef Medline

Williams BM, Luo Y, Ward C, Redd K, Gibson R, Kuczaj SA, McCoy JG (2001) Environmental enrichment: effects on spatial memory and hippocampal CREB immunoreactivity. Physiol Behav 73:649-658. CrossRef Medline

Wright BA, Lombardino LJ, King WM, Puranik CS, Leonard CM, Merzenich MM (1997) Deficits in auditory temporal and spectral resolution in language-impaired children. Nature 387:176-178. CrossRef Medline

Wu GK, Arbuckle R, Liu BH, Tao HW, Zhang LI (2008) Lateral sharpening of cortical frequency tuning by approximately balanced inhibition. Neuron 58:132-143. CrossRef Medline

Yashiro K, Philpot BD (2008) Regulation of NMDA receptor subunit expression and its implications for LTD, LTP, and metaplasticity. Neuropharmacology 55:1081-1094. CrossRef Medline

Yu X, Sanes DH, Aristizabal O, Wadghiri YZ, Turnbull DH (2007) Largescale reorganization of the tonotopic map in mouse auditory midbrain revealed by MRI. Proc Natl Acad Sci U S A 104:12193-12198. CrossRef Medline

Zhang LI, Bao S, Merzenich MM (2002) Disruption of primary auditory cortex by synchronous auditory inputs during a critical period. Proc Natl Acad Sci U S A 99:2309-2314. CrossRef Medline

Zhang Y, Zhao Y, Zhu X, Sun X, Zhou X (2013) Refining cortical representation of sound azimuths by auditory discrimination training. J Neurosci 33:9693-9698. CrossRef Medline

Zhou X, Merzenich MM (2007) Intensive training in adults refines A1 representations degraded in an early postnatal critical period. Proc Natl Acad Sci U S A 104:15935-15940. CrossRef Medline

Zhou X, Merzenich MM (2008) Enduring effects of early structured noise exposure on temporal modulation in the primary auditory cortex. Proc Natl Acad Sci U S A 105:4423-4428. CrossRef Medline

Zhou X, Merzenich MM (2009) Developmentally degraded cortical temporal processing restored by training. Nat Neurosci 12:26-28. CrossRef Medline

Zhou X, Merzenich MM (2012) Environmental noise exposure degrades normal listening processes. Nat Commun 3:843. CrossRef Medline

Zhou X, Panizzutti R, de Villers-Sidani E, Madeira C, Merzenich MM (2011) Natural restoration of critical period plasticity in the juvenile and adult primary auditory cortex. J Neurosci 31:5625-5634. CrossRef Medline 